\title{
'If You Were an Animal, a Plant, a Meal, a Car ... What Would You Be?' The Use of Analogy in the Study of Identity Traits
}

\author{
FLORENTINA SCÂRNECI-DOMNIȘORU* \\ Transilvania University of Brașov
}

\begin{abstract}
The article presents a new data-collection technique that can be applied in identity studies: analogy. The use of metaphor in identity studies is no novelty, but this particular creative exercise used in sociological research has not been described before in the methodological literature. Three pieces of research in which this technique has been applied are presented here: studies in which participants have been asked to analogise the profession of sociologist, a state-owned company, or a privately-owned company with animals, plants, automobiles musical instruments, or types of meals. The article highlights the special features of the analogy technique, such as the fact that it diminishes the control mechanisms of the participants, making the data that are obtained less sensitive to social desirability. The analogy is presented as an unusual and fun technique that breaks up the routine of the respondent's day-to-day life and is a contrast to the monotonous nature of common tests and questionnaires. Applying this exercise in social research is easy. Analogy obtains meaningful answers from participants and it provides valuable results. Because it is able to access surprising information and a very wide range of identity aspects, analogy can be used in all kinds of social research: sociological, psychological, management, political sciences, communication, social work, public relations, human resources, and others.
\end{abstract}

Keywords: analogy, metaphorical thinking, creative methodologies, identity, qualitative data.

Sociologický časopis/Czech Sociological Review, 2019, Vol. 55, No. 3: 347-368

https://doi.org/10.13060/00380288.2019.55.3.470

\section{Introduction}

In this article I will describe the application of analogy in three different research situations: sociologists who make analogies of the profession of sociologists, employees of a multinational company who make analogies of their company, and employees of a state-owned company who make analogies of their company. I will demonstrate how I used analogy exercises, the reactions they triggered in

\footnotetext{
* Direct all correspondence to: Florentina Scârneci-Domnișoru, B-dul Eroilor, nr. 25, Braşov, Romania, e-mail: fscarneci@unitbv.ro.
}

(C) Sociologický ústav AV ČR, v. v. i., Praha 2019 
the participants, the types of data that I obtained, and whether and how these can be used by social researchers.

I applied a creative technique to collect data describing the identity status of a profession and of some companies. The article reports on the application of this novel technique, its methodological consequences, and examples of the theoretical statements about identity that it produced.

Although this is an old technique, the way in which it is applied here is new. Although it is a technique of creativity development, here it is a tool of research. Although it has been used by theorists in the social sciences as a metaphor for reality, here it is constructed by the participants. Although it is considered a game, most commonly applied in job interviews or in marketing, here it is an instrument for revealing identity traits.

\section{The theoretical and methodological background}

Analogy, as a technique, is used mostly for eliciting ideas and for the development of creativity. Onut [2005: 43] lists it alongside one hundred other creativity techniques: 'analogy is when, while dealing with a problem that is not sufficiently understood to be solved, we resort to "importing" knowledge, principles, methods and ideas from a field that we do know, so that we may apply them to our problem'. The term originates in the Greek ana logon (= comparison on the basis of a proportion); ' in formal language, analogy is written as $\mathrm{a} / \mathrm{b}=\mathrm{c} / \mathrm{d}$ and is interpreted as $\mathrm{c}$ is for $\mathrm{d}$ what $\mathrm{a}$ is for $\mathrm{b}^{\prime}$ [ibid.: 47].

In the social sciences, the term analogy is used in parallel with the term metaphor. Because of the established literary sense of the latter, analogy is often the chosen word. In social research literature, the expression that describes these kinds of unusual, inventive approaches is 'creative methodologies'. Lately, we have witnessed an increased preoccupation with making social research methodology more creative (see multisensory research in Powell [2010], multimodal maps in Clark [2011], art-based research and research using technology as described in Kara [2015], sandboxing in Mannay [2016] or the combining of social research with different creative practices in Marres et al. [2018]).

When referring to analogy, the expression 'metaphorical thinking' is also used. Quoting Black, Leys Stepan [1986: 267] shows that 'metaphors join together and bring into cognitive and emotional relation with each other two different things or systems of things, not normally so joined'. An analysis concerning the presence of analogy in the social sciences reveals difficulties in its acceptance as a means of knowledge. In 1986 there was still a debate over the role of metaphor in scientific theory: 'metaphor occupies a central place in literary theory, but the role of metaphors, and of the analogies they mediate, in scientific theory is still debated. During the scientific revolution of the seventeenth century, metaphor became associated with the imagination, poetic fancy, subjective figures and even 
untruthfulness and was contrasted with truthful, unadorned, objective knowledge- - that is, with science itself' [Leys Stepan 1986: 261]. The above-mentioned author shows that in the 1980s only a few scientists were ready to accept analogy as a component of scientific theory: 'some philosophers of science are now prepared to assert that metaphors and analogies are not just psychological aids to scientific discovery, or heuristic devices, but constituent elements of the scientific theory' [ibid.: 262].

As an instrument of social knowledge, analogy can be found in the theories of some renowned sociologists (most of whom are postmodernists). Soreanu [2010] mentions three of the best-known ones: Parson's society as a 'cybernetic system', Goffman's 'theatre', and Bourdieu's 'field'. There exist works that are entirely metaphorical — see the writings of Jean Baudrillard. Leys Stepan [1986: 265] describes 'analogies joining women and the lower races'; these are instruments through which reality is understood: 'the metaphorical system provided the "lenses" through which people experienced and "saw" the differences between classes, races and sexes, between the civilized man and the savage, between the rich and the poor, between the child and the adult'.

Analogy, alongside other research methods, techniques or instruments that were not easily accepted, suffers from a lack of scientific character: 'critics of metaphorical thinking in social science argue that these "devices" are used uncritically and obscure reality because they are too intuitive and too interpretative to be considered scientific' [Rosenthal 1982: 283]. Of course, in recent decades, due to the proliferation of 'qualitative research' and the popularity that it has enjoyed, critical voices concerning less conventional techniques have been, if not silenced, at least less heard.

I have tried to combine the advantages of analogy as a means of understanding reality and as a component of theories with the advantages of using analogy as a creative technique, in order to create a construct that is consonant with social research methodology. I have applied analogy as a creative technique in an attempt to source descriptive theoretical propositions related to the identity of a profession and to the identity of some human entities. I have gathered data from the subjects of the research using analogy exercises; I have processed the data and I have constructed identity theoretical propositions based on it. Therefore, I have kept the idea of understanding the world through analogy, but the analogy is not built by the researcher, it is built by the participants. The theory is empirically based on their experiences and interpretations. I have kept the essence of analogy as a creative technique, that of sourcing ideas, but I have used it to produce qualitative data in a descriptive research.

The analogy was built by comparing (in separate studies) a profession and two companies to an animal, a plant, a meal, a musical instrument, and an automobile. Having studied the English scholarly literature, I can state that this creative exercise has not been used as such in sociological research. Nevertheless, there are circumstances in which this exercise is applied-for example, in 
job interviews, when candidates are asked to make personal analogies with the mentioned elements or with other elements. In such cases, one aims to assess the candidates' spontaneity and their ability to use metaphors and to inventory some identity traits.

In French literature I found an article written many years ago by Bourdieu [1976] describing the results of a survey of the image that the French have of their political leaders. The survey was conducted in the form of a game: the participants were asked to choose a colour, a tree, a profession, a renowned woman, a cartoon character, etc., that best describes French political leaders. This game is called 'Chinese portrait'.

The Chinese portrait is now used in market research as a qualitative projective technique along with other, similar creative techniques, like brand personification, mind maps, scrap art technique, tarot cards, guided imagery, etc. The Chinese portrait is defined as a metaphorical description of something through a comparison with something else.

Nevertheless, this exercise was not described in methodological writing before and I was only able to find one recent conference paper reporting on results obtained using the Chinese portrait in dermatology [Raynal et al. 2017].

However, the use of metaphor in identity studies is no novelty. The bestknown examples are provided by Gauntlett [2007]. He asked his subjects to make some constructions that metaphorically reflect their identity using objects symbolically placed in boxes, or to build something that represents them out of Lego parts (for example, a few plant parts represented a love of nature on the part of the participant who used them, and/or the fact that he/she was a vegetarian).

In the social sciences, the instruments for identity studies have been classified by researchers in the field into direct and indirect tests given the importance of this criterion for studying a relatively sensitive topic such as identity. In the studies presented in this article, analogy can be said to have been used as an indirect test for studying identity. This is because it did not suggest to the subjects that it would be a method used for discovering identity traits.

A short inventory of direct socio-psychological tests for the exploration of the self and of identity [see Ilut 2001: 174-180] would include: the self-esteem test drawn by Rosenberg, various personality tests, Zorgo's valence inventory for identifying the needs, trends, dimensions, or orientations of personality, the 'ways of life' procedure drawn up by Morris to study values and life guidelines, and the personal values test drawn by Vernon and Allport for value identification.

Ilut introduces into the discussion an issue that can occur when direct research methods related to identity and the self are used: "To what extent the subject, being aware of the purpose of the research, reveals "the authentic" from his self-representation, inner values and attitudes. Some sources for distortion have been highlighted in practice, with one of them being common to all direct methods, namely social desirability' [ibid.: 181]. 
The same source indicates indirect tests for studies concerning the self and identity [ibid.: 186-190]: the prior perception theme test, the projective test for self-knowledge and its structuring and restructuring; semi-projective verbal techniques (indirect questions: 'they say that...', 'as if you heard', 'what do you think he/she would say'); the semantic differentiator drawn up by Osgood for selfimage identification and individual and group values; Kelly's repertoire grid test for the study of the self, the personality, the individual conception of the world; the mental scheme for identifying the representation system for objects and aspects of the outside world; the processes based on the principle of selection and the distortions of perception, memory, and judgement for the study of values and attitudes; the process carried out by Christi and Merton for value identification by studying the qualities and characteristics of the people who are held in high esteem by the subject.

Ilut emphasises that although indirect methods exclude some shortcomings of the direct methods, they bring up a new limitation: 'The more a technique is indirect from the perspective of the possibilities of masking the individual, the more uncontrolled variables are interposed, and therefore the less secure the identification of a certain representation or value can be' [ibid.: 197].

Therefore, analogy can be used, in my opinion, as an indirect test for the study of the self, of the personal, and of social identity. It can reveal new information about identity by comparing a person with an animal, a plant, a musical instrument, etc. The test works well not only in the case of self-identification (when it is applied to a person comparing herself/himself to an animal, a plant, etc.), but also in the case of hetero-identification (when other people are asked to make analogies concerning a certain person). Moreover, comparing identity traits resulting from the self-comparison to a car, a meal, etc., to the traits revealed through hetero-identification not only yields spectacular results but also reveals important data on possible identity discrepancies (for example, the difference between subjective and objective identity or between the real and the virtual one; see Goffman [1961]).

The analogy exercise can thus be used in the inventory of 'ideas and feelings one has about his/her identity' (see the definition of identity in Marshall [2003]) or about somebody else's identity, and to establish how somebody is similar to others, how somebody differs from others, and how individuals and communities distinguish themselves from other individuals and other communities in their social relationships (see the definition of identity in Jenkins [1996]). Basically, analogy can reveal information about any of the individual and collective identity referents listed by Muchielli [cited in Jurcan 2005]—for example, about physical characteristics, material and intellectual possessions, origins and the past, systems of values and specific conducts, motivation, interests, attitudes, undertakings and memberships, position in the social hierarchy etc. or about carried out activities, regulations, decision making, evaluation systems, reward and punishment, networking, power styles, role play, cooperation and conflict, hierar- 
chy, leadership, rules of conduct, models and counter models, group representations, etc.

Because this was a sociological research, I used analogy not in the case of personal identification, but in the case of collective identification (the study of the professional identity of sociologists) and the identification of human entities (the study of the identity of some companies). My intention was not only to discover the kind of identity information this exercise gives access to, but also to use it in order to undertake methodological observations related to the application of this technique in research, by making the inventory of the advantages and disadvantages of its deployment.

\section{Methodology}

The first research I will refer to in this article was carried out in 2005 and it was an explorative study on the sociology of sociologists. The database I used included responses from 460 subjects, who were graduates of state and private Romanian universities. The research was conceived and coordinated by PhD Gheorghe Onut ('Transilvania' University of Braşov) and pursued three categories of objectives: to identify who sociologists are, what they do (their occupation) and what they think about sociology, about being trained for the profession of sociologist and about practising this profession. The study was financed by the Romanian state in a grant (CNCSIS A: A Sociologist's Profession and Occupations). The guide containing the questions was comprehensive (58 open and closed questions). The analogy making exercise was a very small part of this guide. The extensive results obtained after the processing, analysis and interpretation of the collected data are to be found in Scârneci [2007] or Onuț [2008].

The second piece of research I will refer to in this article was undertaken in 2008 in a multinational company with its head office in Belgium, with numerous branches in countries all around the world, and with a small branch in the city of Brașov, Romania. The goal was to identify communicative and cultural practices, specific of multinational companies. The larger research project, 'Institutional Language and Intercultural Communication in Multinational Companies in Romania, was conducted by PhD Liliana Coposescu ('Transilvania' University of Braşov) and financed by the Romanian state in a CNCSIS grant. The analogymaking exercise was a small part of the extensive data collected process that included different other methods and techniques. The exercise was completed by 10 employees of the Romanian branch of a company (out of its 21 employees). The extensive results obtained at the end of this study using this specific exercise can be found in Scârneci [2009].

The third piece of research I will refer to in this article took place in 2012 in a state-owned company. The main objective of the research project, whose name I will not mention for identity protection reasons, was the recovery and valorisation of the representations from the collective memory of the people of Brașov 
concerning the beginnings and the historical progress of their relation to the said company and its employees. The project was conducted by PhD Daniela Sorea ('Transilvania' University of Braşov) and it was financed by the company in question. In this project, too, the exercise of analogy-making was attached as an appendix and it was administered to 165 employees holding different hierarchical positions in the given company.

In all three research projects, analogy was used in an explorative manner. I sought to discover whether it yields useful information for social researchers and what kind of data it provides. It all started with the idea that analogy would reveal the identity traits of a profession in the eyes of those who practice it and the traits of some companies (multinational and state-owned ones) in the eyes of their employees.

The exercise was made up of the following questions:

- What animal best embodies the profession of sociologist/the company you work for? Briefly describe how you see this animal (especially characteristic traits, but also its typical actions).

- What plant do you believe best embodies the profession of sociologist/the company you work for? Briefly describe how you see this plant (especially characteristic traits, but also 'preferred' places, 'preferred' company, soil and climate conditions, etc.).

- What automobile do you believe best embodies the profession of sociologist/ the company you work for? Briefly describe how you see this automobile (especially characteristic epithets, but also anything else you find characteristic).

- What meal do you believe best embodies the profession of sociologist/the company you work for? Briefly describe how you see this meal (especially characteristic traits, but also anything else you find characteristic).

- What musical instrument do you believe best embodies the profession of sociologist/the company you work for? Briefly describe how you see this musical instrument (especially characteristic traits, but also anything else you find characteristic).

The qualitative data obtained were processed by classification, using coding procedures with emergent categories (i.e. inductive coding schemes), and then analysed and interpreted.

\section{Findings}

I will indicate here that analogy facilitates access to certain sorts of identity information and I will discuss some methodological observations concerning the application of this technique in research.

First, I consider a drawback of the analogy exercise. It raises suspicion among respondents. Many of them are surprised by such a bizarre request as to compare, for example, a company to various things that are some degree or an- 
other animated. They do not understand the relevance of the exercise, they doubt its power to reveal important scientific information, they think that it is a joke, a mock study. Because of these beliefs, many potential participants may refuse to complete the exercise. Even if the researcher is extremely convincing, the number of refusals he/she faces may be significant, and in the case of less numerous populations, the study would be severely affected by the small number of answers.

I don't know if this difficulty could really be surmounted. Nevertheless, while trying to gain trust in the technique, the researcher should inform the participants that other studies have delivered notable findings using this strange and uncommon exercise. I have noticed that when the respondents manage to overcome the initial surprise and lack of trust, they are quickly attracted by its spectacular nature, by the ease of being able to indirectly and playfully express thoughts and attitudes that they would normally repress. However, I believe that, in studies using analogy, refusal to participate is not a more common occurrence than in other studies that use creative methods and, based on my experience, refusals are less common in studies using analogy than they are, for example, in visual studies where the adult participants are asked to draw.

The exercises may also be perceived by some participants as connected with psychology. They might believe that the interpretation of their responses is meant to be some sort of psychoanalysis, and as a result, they might disregard them and refuse to take part in the study. Analogies can also lead to unpleasant feelings for the participants when they are being asked to apply the exercises in relation to matters they do not appreciate (for example, personal analogy in the case of a participant with low self-esteem or an analogy concerning a company in the case of respondents who are not proud of their workplace). I encountered such a situation in the case of a state-owned company, where most of the answers were given with little enthusiasm and were very short, sad, or indifferent.

Nevertheless, analogy brings interesting answers that are delightful for researchers to work with. When you discover the various exotic animals, plants that sting, rare musical instruments, luxury cars, local meals, etc., enumerated by the respondents, you first imagine how much fun they must have had completing the exercise. Then, many ideas start coming to you, generated by the symbols that accompany, for example, the resemblance between a profession and a climbing plant or that between a company and a Rolls Royce. Things settle down a bit when you make an analysis of the characteristics that accompany the enumerations of animals, plants, etc. They reveal the exact symbols indicated by the respondents and provide a complete portrait of the studied materials, made up of new and unexpected data.

Here are some examples that illustrate the results obtained after a brief processing of the data collected with analogy. In the perception of the people in management positions in the state-owned company, the animals that most resemble the company are prehistoric animals, i.e. dinosaurs and mammoths, big, strong animals, such as bears and lions, or only slow ones, such as the tortoise. 
The management generate the impression that the institution they work for has now become a body that is not fit for purpose, it is very powerful, but it is also slow-moving. (probably because of its dimensions). The characteristics of these animals enhance the impressions created just by enumerating them: power, constancy, but also gives the impression of power and sturdiness, moves rather slowly, but is determined, can be immovable, and so 'long-lasting' that it no longer suits our times, anachronistic, belonging to the past.

In the view of sociologists, their profession resembles some kinds of climbing plants (ivy, creeper), certain plants with thorns (cactus, rose, leech) and some trees (oak, fir). The plants are not exotic, they are rather common, the kind that can be easily overlooked. They are neither interesting nor even beautiful (although most are decorative and ornamental). They are plants that 'do' something (things that are not pleasant): they hang, sting, prick, pinch. They are not demanding plants; they do not need special attention to grow. They are wild, they grow by themselves. They are not essential for human beings, they aren't even useful.

Regarding the kind of meal most often mentioned in relation to the profession of sociologist, it is a combination of as many ingredients as possible: pizza, mixture of vegetables, salad, broth. The food is traditional, autochthonous, popular: stuffed cabbage, polenta, beans with smoked meat, meat soup, vegetable stew, French fries. Rarely, they mentioned: caviar, French cheese. The food mentioned is spicy, flavourful, and tasty. The dishes are tasty, but common (not at all interesting, with little visual appeal, served to family members, not to guests one aims to impress). The food is not sophisticated, nor difficult to prepare, it uses spices and local ingredients.

The musical instrument that appears most in the exercise completed by the multinational company's employees is the piano (an important instrument in the economy of an orchestra, that can very well be independent, autonomous and can easily be used for solos). Other instruments mentioned include guitar, organ, flute, cembalo, and saxophone.

What seems to be a fundamental characteristic of the company starting from the enumerated attributes of the instruments is independence and autonomy. The company is adaptable, it works very well on its own, but it can also team up with other companies (it can support solos without a problem, but it sounds excellent with an accompaniment too, it sounds good in an orchestra, but its solo is remarkable, it can make music by itself or with other instruments). The autonomy derives from offering multiple, complex services that cover all the client's needs (it is diverse, complex, it has a wide range of tones, it is a complete instrument, with a wide range of acoustic coverage, it can play any melody without accompaniment, it has low, high and medium sound, it has many octaves).

The company is high class, it distinguishes itself from other companies (it is expressive, it has a special manner, style, personality, it is an elegant, respected instrument). Also, its products are of high quality (the sound carries well, is warm, has perfect musicality, it is more melodious, easily assimilated by the majority of people, it is 
strong, clear). The company is perceived as being well structured, easy to work for (it is organised, one can adapt quickly to working in it), but its overall performance depends on the performance of each employee and all of them depend on the performance of the manager (if it is well tuned and used in the right way and by the right person, it generates harmony only if each string sounds good).

The cars that represent the company are not at all common, they are elegant, distinguished, very beautiful, even spectacular, expensive, and strong (Subaru Forest, Lexus Hybrid, Porsche, Audi A3 and A4, Rolls Royce, Alfa Romeo 149, Volvo S40). The sense of elegance and class is amplified by the fact that employees specify colours that are not often used for mainstream cars, but are instead specific to VIP cars (black, metallic black).

The characteristics of the cars that are mentioned mirror those of the company and are related to power (powerful, powerful engine, top class, great power, can take on any challenge, very good performance, speed), reliability (driving stability, the type of suspension borrowed from Formula One cars offers a smooth and precise ride, robust, safe, resistant), elegance and refinement (beautiful, delicate, decent design), neat appearance, and even luxurious (hand crafted interior finishes, leather upholstery). It is fully equipped to work without problems and to satisfy the clients (silent, low fuel consumption, comfortable, spacious, full option, surround sound system with 8 Bose speakers, characteristics that make you become one with it the moment you sit in the driver's seat and fasten the seat belt, cutting edge technologies, client service is an important part of the sales strategy).

It is acknowledged and very appreciated by others (there is no way a person can resist it, it can sprint while attracting the admiring looks of the passers-by, it is in the top 5), or even a bit too classy for Romania (competitive even if the competition is not too famous, useless on Romanian roads, but nevertheless recognised for its value by the Romanians, too, it can be used to its true value by those who benefit from a more developed industry). It is expensive and a bit exclusive (there are few clients and the price is high).

Simple looking at the way the answers are being presented and their concise processing shows that part of the reason why the exercise yields reliable results is because it significantly differs in the three situations presented. The most spectacular difference is the completely opposite way in which the employees from the private sector refer to their company compared to the people who work for the state. The multinational company's employees have positive representation and a favourable attitude towards the company they work for. They acknowledge its principle and appreciate its guiding values: competitiveness, quality, performance. They give the impression that they are even a bit stressed by the importance and the class of the company they work for, they seem to be somewhat unsatisfied that they are involved only in the executive part of the company's activity. All in all, there is not much that bothers them about the company, and they mostly praise it.

Regardless of the position they occupy in the state company, the employees perceive the company as being very old, large in size, and resembling other Ro- 
manian 'products' (it is a representation of Romania-it looks like the country, it operates accordingly, etc.). The company is characterised by the variety and diversity of its components from organisations to services, and from offices to people. The false impression it gives was mentioned by most of the employees (it is not what it seems to be, its appearance is deceiving, it seems completely different from the outside- it is always better on the outside than on the inside). It is clear to everyone except the managerial staff that the company is being drained, that it is being pillaged, and everyone in a position to exploit it does so without any remorse and with the blessing of 'the centre'. The company is not a perfect workplace, but it is secure. The employees do not give it too much praise, but they do not curse it either; they prefer to be spectators to the changes happening in the company, and they are aware of their helplessness in relation to the 'the mammoth' (but they also manifest a lack of involvement and slight indifference towards it). The company is perceived as being powerful and strong; it seems that nothing can destroy it, that it can withstand anything, and pays no attention to the people in it. The human resources policy is not trusted. There are many who believe that people are employed with total disregard for their training and qualifications, and that people who are no longer right for the job are nevertheless kept on.

Making analogies reveals all kinds of identity information (see individual and collective identity components in Muchielli [cited in Jurcan 2005]. Here are some of the results of the interpretation of the data collected in the study about the profession of sociologist. The notion of obstacles is common to all the epithets and specific actions that were mentioned by sociologists about sociologists. Sociologists are strong, they endure the toughest obstacles. They are equipped with the most diverse accessories, which help them to face and overcome all the challenges that confront them. The idea of adaptability also generally applies. Sociologists are almost irritatingly adaptable, they go beyond the expected, finding solutions that help them to overcome limitations and difficulties. They are not demanding, they give the impression of being easily content. Another common feature of theirs is the combination of elements he/she is made up of. The sociologist is an amalgam, a strange mixture of elements that make him or her unusual and unique. Sociologists are not at all simple, they are rather complex and surprising. One can never know what to expect of them, they can be innovative at all times, always giving unexpected answers. In general, sociologists are presented as dynamic, full of life, and always in action.

When data from many people are gathered by making analogies, it is possible to perform interesting comparisons according to different socio-demographic criteria. For example, while studying sociologists I was able to reveal regularities in the perception of this profession depending on the university centre that the respondents graduated from and the generation of graduates they belong to (before or after 1989). If we consider, for example, a comparison between sociologists who graduated before 1989 and those who graduated after 1989, it can be said 
that what differs for the older generation is the effort and the investment made by the sociologist in order to become what he or she is: effort, hard work, results are strenuously obtained, the sociologist struggles, grows with difficulty, rarely flourishes, he/she needs special conditions to grow, cannot grow just anywhere. This category of sociologists also brings up the issue of usefulness: less useful, the investment is not worth it, with touch-ups, he/she can become useful, important, the sociologist has an eye for everything, but to no use, it does not last long, he/she is flamboyant, pointless, apery. I also noted, for example, differences between the analogies made by the graduates from private universities compared to those made by graduates from state universities or between the analogies made by female sociologists compared to male sociologists.

Likewise, I found significant differences in perceptions in terms of the position occupied by the respondents within the state company. The workers express their appreciation or contempt towards the company more directly, they more often characterise the work they carry out in the company and the products offered than the company itself. The lower they are in the hierarchy and in training, the more highly they think about the company and the more grateful they are to have a place to work in the company. Similarly, the closer they are to the consumers than to the institution, the more clearly they see its benefits.

The analogy exercise reveals suggestive descriptions of the way something or somebody is perceived. By applying the exercise I discovered information about the organisational culture, the management style of the companies, the place they occupy among other companies, about their past and future, about the advantages and disadvantages of working for those companies, about dissatisfactions, expectations and frustrations, about attitudes towards the companies, work colleagues, and the work performed within the companies, about their strengths and weaknesses, and about the opportunities and challenges they face.

As mentioned above, analogy should be used in descriptive studies. Basically, it facilitates insights (such as who the real boss is in a company or who the privileged employees are). It helps reveal feelings about something or someone and the reasons for these feelings, and the types and characteristics of relationships between people, organisations, events, and processes. For example I discovered that in the multinational company the relationship between managers and subordinates is very close (like the one between cats and their owners); that the participants sensed a large distance between them and the people making important decisions; and that despite looking like the ideal job, the multinational company gives its Romanian employees, as well as competition and excellent working conditions, reasons for discontent and frustration.

It is worth pointing out that if the researcher is familiar, for example, with the organisation under study and with its employees (because he/she works there too or because he/she has previously applied in the field other methods like observation or interviews) he/she could recognise in analogies and in their explanations real employees or managers, real events or tasks, real situations or 
places, real tools or practices, etc., which are openly described by participants, which are praised or criticised without constraints generated by shame, desirability, or fear. Thus, analogy can be a useful technique in applied research situations and it can be used in action research projects. These findings also reveal two methodological observations: results are more explicit and more informative if (1) the researcher is familiar with the people or the human entities that are being analogised or if (2) the analogy is accompanied in the same piece of research by other methods and techniques of data collection.

Coming back to the results obtained by means of analogy, one might argue that other techniques could also reveal these elements of social life. What makes analogy special could be the deep and sometimes even socially undesirable feelings that it uncovers (like hate or extreme hostility), the detailed characteristics that it reveals, the hidden motives that it allows to be known, and the always surprising character of the obtained results.

For example, as a researcher, you imagine that you will gather information about the advantages and disadvantages people working in multinational companies have, but you are really surprised to find that Romanians feel discriminated against compared to employees of other nationalities. The person who is applying the analogy exercise has to expect important surprises, including a deviation away from the original purpose of the data collection. For example, it is possible that at the time the exercise is being applied a certain event will have just taken place in the company, a dismissal, a resignation, a new regulation, or a controversy, etc., around which the analogies are developed, overshadowing all the other identity information the researcher would normally access. But this is the danger of any indirect research method, and the sensitivity to context is a common shortcoming of qualitative methods and techniques.

For this reason, the comparing of results obtained by making analogies in different research situations must be carefully managed by paying special attention to the contexts in which the exercises were applied. Generalisations related to the results obtained by applying analogy are also hard to grasp.

The most important asset of the analogy technique is the opportunity it gives respondents to provide information that normally, with the use of other techniques, they would not provide. It is much easier to describe an animalwith the good and the bad-than to directly describe the company one works for; it is much easier to enumerate the flaws of a car than to openly refer to those of a person, etc. It was a surprise for me to see how easily I was able to obtain unrequested information using analogy-for example, about managers considered corrupt or unfair, about the preferential employment of colleagues, etc.

In short, analogy facilitates deep knowledge and understanding (deeper understanding than what we could gain by applying other qualitative techniques like in-depth interviews) of things difficult to access. I think that the fact that we can approach more easily what otherwise is harder or impossible to obtain is the main contribution of analogy to enriching sociological knowledge. 
This advantage of the technique is also important when making comparisons between the answers given by different categories of respondents. You have the opportunity to uncover important dysfunctions, differences not only in perceptions but also in the philosophy and actions between, for example, the management and the 'working class' in the company. The exercise can show, for example, that one of the owners sees the company as an elephant, whereas the other sees it as a little mouse, or that the managers see the company they work for as a giant sequoia, while ordinary employees compare it to a pansy, etc. (see identity discrepancies in Goffman [1961]).

Another important methodological observation I made is that the outcome is rich, relevant, and interesting mostly in the case of educated respondents. The exercises work very well with this type of subjects; they work well with metaphors, and their answers are more consistent, complex, and significant. Unfortunately, applying them to less educated participants is more difficult. I reached this conclusion by comparing the answers given by the participants occupying different positions in the state-owned company. The lower I went in the company hierarchy, the less interesting and poor in symbols the answers became. This observation has a theoretic foundation. Onut [2005: 47] notes that 'analogy is founded on our mind's ability to produce and deal with metaphors. Metaphors are likely to be used by creative and cultivated people'. The same author quotes Aristotle, who 'stated that complete mastery of the metaphor is the strongest indicator for genuine intellectual excellence' [ibid.: 49]. This shortcoming can be removed to a certain extent by applying the exercises during the interviews. In that case, the researcher can ask additional questions that can elicit responses (for example, 'what kind of car is it?', 'how is it driven?', 'on what kind of roads can it be driven?').

No other significant variations between groups of social actors have been noticed when working with this exercise. I think that other creative techniques, like the visual ones, for example, create more discrepancies between the participants' ability to deal with uncommon research tasks. For instance, I discovered that the older people are, the more resistant they are to visual techniques, or that the drawing technique may be more suitable for women than for men [see Scârneci-Domnișoru: forthcoming].

Nevertheless, some differences in data richness when using different analogies were certainly discovered. Different people with different experiences and interests generated more or less profound and valuable responses. Thus, different analogies had different effects on the data-gathering process and the particular social positions and experiences of participants influenced the data obtained from them.

For example, the analogy with the musical instrument was the most difficult one for the respondents and it revealed the least information to the researcher. The answers to this analogy were the least consistent in my studies, it puzzled the respondents and, therefore, after the first two studies I no longer apply it. The reason for which this analogy is less useful could be the low musical culture of the respondents; most people are not very familiar with instruments. By contrast, 
the analogy with animals was the most fruitful one; it worked well, as animals are common in people's lives and they are often culturally used in proverbs or fairy tales. As an anonymous reviewer of this article suggested, the animals are anthropomorphised and we can expect that most people associate them with certain attributes (the clever fox, the powerful lion, the dirty/lazy pig, etc.).

For this reason the requested analogies must be from fields that respondents are relatively familiar with. I found out, for example, that some of the women had difficulties in formulating analogies with cars. Their answers regarding cars were less precise (unlike Subaru Forest, Lexus Hybrid, Alfa Romeo 149, Volvo S40), they gave fewer specifications regarding the engine capacity or other technical data, but still they referred to comfort, consumption, reliability etc. Therefore, I believe that when choosing which analogies to apply, one should take into account the characteristics of the respondents and adapt the analogies according to the respondents' knowledge and interests. For example, if the participants are men that work in service stations, then analogies involving musical instruments will be of no use. In this case, analogies relating to car components or mechanical tools could be tested. Likewise, in the case of writers or literature teachers, analogies relating to novels could be employed.

Thus, the chosen analogy exercises must involve a comparison of familiar elements: on the one hand the self, the respondent's own profession, his / her own workplace, etc., and on the other hand common elements, specific to our lives (animals, plants, cars, etc.). Another important methodological observation should be emphasised here: analogy is a very flexible technique-anything can be compared with anything. Not just a person or a human entity, but even, for example, a disease or someone's future could be analogised not just with animals or plants, but even, for example, with pieces of furniture or film characters and so on.

Regarding the structure of the analogy exercise, I have also discovered that each analogy reveals different identity traits. It is possible to get one kind of information from an analogy with an animal, such as data about physical characteristics or specific actions, and other kinds of information from an analogy with a plant, such as data about affiliations or lifestyles, or an analogy with an automobile, such as information about relations or management style, etc. Thus, the methodological conclusion would be that it is best not to use a single analogy. In order to find as many and as different identity aspects as possible and in order to deliver a complete identity image of the studied aspects, the analogies must be multiple. Of course, it is also necessary to take into account the comfort of the respondents, who might get bored or tired and, in the end, might refuse to make infinite analogies. My opinion is that the ideal number is to use four or maybe five analogies in order to obtain enough information without overwhelming the participants.

As I have emphasised before, the participants must be familiar with the proposed analogies. But it is worth mentioning that ordinary elements used to make analogies must be familiar to the researcher as well. I confess that I had serious difficulties in interpreting the answers of male participants who accu- 
rately defined things about which I had no knowledge in an analogy with cars. My work became much more difficult because I could not understand what they were referring to. I had to spend many hours searching on the internet to find out, for example, what an ' $\mathrm{X} 5$ ' is, what it looks like, how expensive it is, etc. The actual problem was not the time spent doing internet research, nor any difficulty performing the analysis, but a fear of misinterpreting the data. Not only should the researcher know the elements of the analogy well, but it would also be advisable that he/she originate from the same culture as the respondents, in order to render the misinterpretation of the symbols conveyed by the subjects less likely (more about this later in this article). For example, in Western culture a dog is a useful animal, one that is appreciated and loved. But in India, dogs are considered among the dirtiest and most miserable animals; they are associated with vagrancy because there are many stray dogs in urban areas [see Literat 2013].

In order to limit as much as possible the errors that can occur in the process of data analysis and interpretation, analogy is accompanied-as can be seen in the requirements for the exercise described above-by explanations. Respondents are asked for details that explain why the leopard, nettle, black caviar, Trabant (a Romanian car), etc., was chosen. I also discovered that just analysing the list of plants, animals, and so forth, without also analysing the explanatory answers can sometimes lead to data misinterpretation. One person may think of an animal as being harmless, while another might have had unpleasant experiences with the same animal; a plant can for someone bring back beautiful memories, whereas someone else may be completely indifferent to it; one person might consider a certain kind of meal very tasty and flavourful, while someone else may say of the same meal that it is disgusting, and so on and so forth. That is why it is advisable for every analogy to be accompanied by short explanations that can clarify the way the animal, the plant, the car, etc., is perceived by the respondent. The explanations related to their characteristics make the results more valid and accurate.

I can conclude, from the mere enumeration of the animals, plants, cars, and kinds of meals the respondents used to make analogies to the profession of sociologist that the sociologist is a common person, someone who does not stand out, who would not be noticed in the street. Sociologists look ordinary, they are not spectacular or impressive. There is nothing special about them, they rather lack importance, they are not imposing, elegant, extravagant, or classy. They are not pleasant, nice, or comfortable to be around. They are rather annoying, tiresome, caustic. They are not demanding, they are low-maintenance, they can handle difficult conditions. They are not indispensable, and they might not even be useful, but having them around can look good. Nevertheless, they can adapt to various needs and they can turn out to be quite an asset. They are strong, not easily set back, sly, and resistant. Although many of the things that I have discovered coincide with the results obtained after analysing the respondents' additional explanations, some ideas that were developed from the enumerations of the animals, plants, etc., contradict the ideas discovered by means of the epithets and actions. 
For example, it turned out that the sociologist is elegant, fast, imposing, and even nice, not icky and slow as the initial analysis had revealed.

More technical matters of data processing and analysis will be dealt with now. In studies using analogy, the first step is to classify the analogies, to make a structured inventory of animals, plants, meals etc. For example, animals can be categorised as follows: small, medium, and large animals, strong and weak animals, or domestic or wild animals, or animals that are bold, that inspire fear, that have no natural enemies, that are fast, intelligent, or smart creatures. These classifications are useful because, sometimes, quantifications are suggestive. For example, are powerful or weak animals predominant?

Objective criteria should be used for classifying analogy nouns, but context-guided classifications cannot be avoided. In my view, classifications are very much dependent on habitus. As noted above, the researcher should come from the same culture as the participants because in this way he/she will be familiar with the contextual characteristics of the animals, plants, meals, etc., the participants use in their analogies. If the researcher comes from the same culture as the participants, then everyone involved in the research will already be accustomed to the same local sayings and proverbs about animals and plants or to the same observations and jokes about the performance of a local car. Equally, they will all have tasted local foods, made with local ingredients, and will be well-acquainted with any ancient foods that have unusual histories or are accompanied by strange legends and so forth. That is why classifications can be very much contextual and classifications made by a researcher from one culture might easily be contested by researchers from other cultures.

As an example of this, in a previous version of this article I wrote the following paragraph in which I mention some classifications and an anonymous reviewer questioned the coherence of the groups that I had created. Here is the paragraph:

The animals enumerated by the graduates of private universities have one thing in common-they are not flattering. They are the only ones who mentioned: pig, donkey, rat, fox, dragon. The animals enumerated by the male sociologists have the characteristic of evoking unpleasant feelings: vulture, jackal, crocodile, crow, owlet, owl, octopus. The other animals they enumerate tend to incite goodwill, through their helplessness-pigeon, rabbit, camel, giraffe-or by not being taken seriously: ape, parrot, squirrel, dolphin. Female sociologists enumerate strong or smart animals: lion, elephant, tiger, leopard, horse, bull, black goat, deer, stag (the same goes for the birds: aquila, eagle, pigeon hawk).

The reviewer asked me how the groups of analogy nouns were created and why the dolphin was in the same group as an ape, parrot and squirrel. He/she asked me why I characterised these animals as 'not flattering', 'evoking unpleasant feelings', as 'helpless', and 'not being taken seriously'. He/she asked me how I could prove that the dolphin is not taken seriously, that the camel is seen as helpless, that the dragon is not perceived as flattering, that the bull and black goat 
are considered smart or that a vulture evokes unpleasant feelings. The answer is that I classified and labelled the nouns according to the feelings that they evoke in me as a Romanian who was born and who lives in the same culture as the participants, where dolphins are still used in shows for children and where the vulture is associated with death or dying bodies. Therefore, I think that one should handle with caution any cross-cultural research that involves analogy.

In addition, classification issues can appear even when the researchers and the participants come from the same culture. As noted above in this article, analogies are also very much influenced by personal feelings and experiences (such as what one participant or another thinks about a plant, feels about an animal, knows about a meal, or has experienced with a car) and by particular contexts (such as an event that happened right before the analogy exercise was performed-for example, if a colleague has just been hired or fired, or a manager has just imposed new rules). Thus, an animal, for example, could mean one thing to one person and something else to another person; likewise, even for one and the same person an animal could have a particular meaning in one situation but in another situation mean something else.

A methodological consequence of this issue is that other researchers or participants can justly contest classifications of analogies. This is perhaps why the results of a study using analogy are mostly based on the analysis of the explanations the participants offered and not just on their analogies. For example, results tend to describe the attributes and actions of animals in detail and the animals themselves only briefly. Thus, the results are not determined by the nouns and their classifications as such but by the nouns in combination with the additional explanations. As emphasised further above in this article, analysing participants' explanations for each and every analogy they make neutralises the subjective classification and interpretation of nouns. The noun groups indicate the general perception of the person or the entity being analogised, but they don't have much value and meaning in themselves; the essence of the results is drawn from the additional explanations (which are processed and analysed like any other qualitative textual data).

In order to reduce subjectivity, the processing, analysis, and interpretation of the data should be done simultaneously by at least two researchers; they should discuss differences that occur in classifying and labelling and in ascribing meaning (see investigator triangulation, which is also advisable because we deal with a metaphorical exercise that conveys symbols). It is also best that the data interpretation be subjected to additional examination, such as checking the results with the respondents.

Since I have mentioned the criteria of validity, reliability and credibility, it is also worth noting that, ideally, analogy should be used along with other methods and data-collecting techniques (see triangulation). As we know, data about the same subject, phenomenon, event, etc., (in this case referring to identity) collected using different methods and techniques within the same project mutually complete and verify themselves. 
In my study about the profession of sociologist I had the opportunity to compare the results obtained through analogy to the results obtained by applying other methods. For example, I comparatively analysed the answers a participant gave in the analogy exercise with the answers the same participant gave when asked to talk about his or her own living space and about the way it differs from others' living spaces. I also thought of this question as an indirect test for studying the same professional identity (see Scârneci-Domnșoru [2013] for a complete inventory of the results obtained after analysing the answers referring to the living spaces of sociologists). The identity traits that I discovered using this method resembled those found using analogies. For example, I discovered that sociologists are unusual people, they are spiritual and look for beauty in all things, they are aware of their own value and they are proud of what they have become. They are observant, they possess a sense of self-irony and an interest in intellectual pursuits.

This does not mean that analogy alone does not yield specific information. As mentioned above, the character of the data obtained by analogy is specific in its own way; for example, it is more profound and detailed.

\section{Conclusion}

In this article, I have endeavoured to present a new data-collection technique that can be applied in studies concerning the various identity aspects of individuals, communities, and human entities.

I have proposed analogy as a 'creative methodology', as an innovative technique that could be placed alongside others found in recent methodological literature (see Mannay [2016] and the other authors mentioned in the introductory part of this article). This technique is special not just for its novelty but also because the innovation it proposes is not the result of recent technological progress or some new kind of data recently considered meaningful in social research like visual or multisensory data. The analogy facilitates the collection of simple textual data by classical means (the researcher asks and the participants respond orally or in writing).

It offers a new way of collecting identity-related data and I think that it could be placed alongside other indirect identity tests (see Ilut [2001] or the creative techniques developed by Gauntlett [2007]). But it is a special indirect test because it operates with unusual but simple and familiar elements like animals or meals and many participants (regardless of their socio-demographic characteristics) can happily and easily work with them.

I have used analogy in more than one research situation, and subsequently I have also tried to critically analyse it. I have sought to transparently interpret data obtained by means of analogy to minimise the critics of the 'metaphorical thinking' approach of the social [see Rosenthal 1982]. 
I have shown how analogy is applied, what kind of results it produces, and what the advantages and disadvantages of using it in social research are. Because of the surprising results it renders and the very wide range of identity aspects that it accesses, analogy can be used in all kinds of social research: sociological, psychological, management, political sciences, communication, social work, public relations, human resources, and others.

Analogy can be employed in explorative and descriptive research. It can be used as the main or sole technique when data is being collecting from many respondents. In the case of smaller populations, due to the relatively schematic nature of the answers obtained by means of analogy, it can be used alongside other methods and classic techniques for the study of identities.

Completing the exercise is not time-consuming, it is pleasant and not very demanding for the participants. It is an unusual and fun technique that breaks up the routine of the respondent's day-to-day life and it contrasts with the monotonous nature of common tests and questionnaires. The answers it is able to get from participants are meaningful, despite the fact that they are indirect. It diminishes the participants' control mechanisms, making the obtained data less sensitive to social desirability.

Processing and analysing these data do not pose any particular challenges for researchers who are used to working with qualitative data. At the same time, the interpretation of the data, though made more complicated by the metaphorical nature of the answers, can , in my opinion, render results of a scientific nature.

In conclusion, I see no reason why analogy should not be accepted among data-collecting techniques. In some research situations, this technique can turn out to be essential. Take, for example, cases in which other techniques have not yielded the expected results, in which the respondents are sick and tired of applying classical methods and techniques or in which there is excessive uniformity to the opinions expressed by the participants.

This is the first methodological article ever written about the analogy technique and it is meant to contribute to methodological renewal. With this paper I join those who 'prioritize the development and use of innovative research methods' [Jewitt et al. 2017: 106] and I try to counter the sceptics who 'consider methodological "innovations" as exaggerated fads, more concerned with "novelty" than "an effort to inform"' [ibid.]. I join the trend that seeks methodological creativity by proposing a thick description of a new data collecting technique and submitting it for peer evaluation and criticism.

FLORENTINA SCÂRNECI-DOMNIȘORU is an associate professor at Transilvania University of Brassov, Romania, in the Social Sciences and Communication Department and has a PhD in sociology. Her research and teaching focus on qualitative methods, identity, and visual sociology and she is very interested in innovative research techniques. Her latest book (the first one ever published in Romania about visual research) is Visual Data in Social Research (Cluj University Press, 2016 ). 


\section{References}

Bourdieu, P. 1976. 'Un jeu chinois (notes pour une critique sociale du jugement).' Actes de la Recherche en Sciences Sociales 2 (4): 91-101, https://doi.org/10.3406/arss.1976.3467.

Clark, A. 2011. 'Multimodal Map Making with Young Children: Exploring Ethnographic And Participatory Methods.' Qualitative Research 11 (3): 311-330, https://doi.org/10.1177/1468794111400532.

Gauntlett, D. 2007. Creative Explorations: New Approaches to Identities and Audiences. Abingdon: Routledge, https://doi.org/10.4324/9780203961407.

Goffman, E. 1961. Stigma. EngleWood Cliffs: Prentince Hall.

Iluț, P. 2001. Sinele şi cunoaşterea lui: teme actuale de psihosociologie. Iaşi: Polirom.

Jenkins, R. 1996. Social Identity. London: Routledge.

Jewitt, C., A. Xambo and S. Price 2017. 'Exploring Methodological Innovation in The Social Sciences: The Body in Digital Environments and the Arts.' International Journal of Social Research Methodology 20 (1): 105-120, https://doi.org/10.1080/13645579.2015.1129143.

Jurcan, D. 2005. Identitate şi societate: modele aspiraționale în tranziție. (Identity and society: aspirational models in transition) Cluj-Napoca: Eikon.

Kara, H. 2015. Creative Research Methods in the Social Sciences: A Practical Guide. Bristol: Policy Press, https://doi.org/10.2307/j.ctt1t88xn4.

Leys Stepan, N. 1986. 'Race and Gender: The Role of Analogy in Science.' ISIS 77 (2): 261-277, https://doi.org/10.1086/354130.

Literat, I. 2013. "“A Pencil for Your Thoughts": Participatory Drawing as a Visual Research Method with Children and Youth.' International Journal of Qualitative Methods 12: 84-98, https:// doi.org/10.1177/160940691301200143.

Mannay, D. 2016. Visual, Narrative and Creative Research Methods. Application, Reflection and Ethics. Abingdon: Routledge, https://doi.org/10.4324/9781315775760.

Marres, N., M. Guggenheim and A. Wilkie (eds). 2018. Inventing the Social. Manchester: Mattering Press.

Marshall, G. (ed.). 2003. Oxford dictionar de sociologie. Bucharest: Univers Enciclopedic.

Onuț, G. 2005. Mașina de idei. Dicționar de tehnici creative. (Ideas' machine. Creative techniques dictionary) Bucharest: Editura Fundației PRO.

Onut, G. 2008. Profesia de sociolog. (The profession of sociologist) Braşov: Editura Universității 'Transilvania' din Braşov.

Powell, K. 2010. 'Making Sense of Place: Mapping as a Multisensory Research Method.' Qualitative Inquiry 16 (7): 539-555, https://doi.org/10.1177/1077800410372600.

Raynal, H., M. Delaigue, J. Gardelli-Court, C. Pedre, D. Nathalie, V. Hauet and P. Guillem. 2017. 'Symbolic Representation of Hidradenitis Suppurativa Through the Use of a Chinese Portrait: Crossed Views from Patients, Family Relatives and Healthcare Givers.' Experimental Dermatology 26 (S1): 37-38.

Rosenthal, D. 1982. 'Metaphors, Models and Analogies in Social Science and Public Policy.' Political Behavior 4 (3): 283-301, https://doi.org/10.1007/BF00990109.

Scârneci, F. 2007. 'Ce cred sociologii despre profesia de sociology.' (What sociologists think about the profession of sociologist) Pp. 361-366 in Colocviul international de ştiinte sociale - ACUM 2006, edited by C. Coman. Braşov: Editura Universității 'Transilvania' din Braşov.

Scârneci, F. 2009. 'How Romanians Feel and Think About the Multinational Company They Work For'. Pp. 7-21 in Intercultural Communication in Multinational Companies, edited by L. Coposescu. Braşov: Editura Universității 'Transilvania' din Braşov.

Scârneci-Domnișoru, F. 2013. "“Romanian Sociologists” Identity as Reflected in their Stories about the Space They Live In.' Socialiniai Tyrimai (Social Research) 2 (31): 70-80. 
Scârneci-Domnișoru, F. Forthcoming. 'The Relevance of Visual Data in Social Research.' In Visual Techniques Applied in Social Research, edited by F. Scârneci-Domnișoru. Frankfurt am Main: Peter Lang.

Soreanu, R. 2010. 'Metaphor in the Social Sciences: Creative Methodologies and Some Elements for an Epistemological Reconstruction.' Studia Universitatis Babeș-Bolyai, Sociologia 1: 239-254. 